\title{
Surface texture of Inconel 718 after electrical discharge machining assisted with ultrasonic vibration of a tool electrode
}

\begin{abstract}
Inconel 718 is one of the modern materials widely used in the aviation and space industry, due to their excellent mechanical and chemical properties at elevated temperatures. These parts work in difficult conditions and they are required to be characterized by good accuracy and high quality surface finish to ensure greater durability and fatigue strength. Conventional machining of these materials is difficult and ineffective due to low thermal conductivity of the alloy. Electrical discharge machining (EDM) is often used to machine materials regardless of their mechanical and physical properties. In this process material is removed from the workpiece through series of electric discharges occurring in the sparking gap between a tool electrode and the workpiece. The physics of removing material from the workpiece is completely different from other traditional machining methods, and its effects determine the functional properties of the surface layer. The purpose of the experimental research was to investigate the influence of machining parameters on surface texture of Inconel 718 after electrical discharge machining assisted with ultrasonic vibration of the tool electrode (EDM+US). The study was carried out with a design experimental methodology. Input parameters were discharged current I and pulse duration ton. Roughness parameters $\mathrm{Sa}, \mathrm{St}, \mathrm{Sz}$ were designated for each machined surface.
\end{abstract}

Keywords: EDM+US; ultrasounds; Inconel 718; surface roughness

\section{Introduction}

Currently, successive development of materials engineering is observed, which offers new materials with unique properties. Their rational implementation in industrial applications depends on the development of efficient methods of their machining. The aerospace industry, where these materials are used, constantly sets new, rigorous requirements on machining accuracy and quality of surface finish. Elements manufactured for these industries are made of special, difficult to machine alloy and composite materials, which are characterized by very good mechanical and chemical properties at increased temperatures. Effective machining of difficult to machine materials with satisfactory performance and surface finish is difficult, and in some cases almost impossible to achieve by traditional methods of machining. Due to the above reasons, unconventional methods of machining are becoming increasingly popular in manufacturing processes, i.e. electrical discharge machining, which allows machining of materials regardless of their mechanical and physicochemical properties $[1 \div 6]$.
In the electrical discharge machining material ,is removed from the workpiece as a result of electrical discharges between the tool electrode and the workpiece immersed in the liquid dielectric, which lead to melting of the material and its evaporation. As a result of the impact of thermal effects that lead to the loss of material, the shape of the working electrode gradually replicates on the workpiece $[2,4]$. The physics of removing material from the workpiece is completely different from other traditional machining methods, and its effects determine the functional properties of the surface layer. Electrical discharge machining is mainly used to manufacture difficult to machine objects with complex geometrical shapes, e.g. injection molds, forging dies, as well as parts used in the aerospace and nuclear industries $[7 \div 9]$.

In order to improve the technological indicators of manufacturing processes, new varieties of hybrid electrical discharge machining are developing, which rely on the simultaneous interaction of various mechanisms or sources of energy. One of their variations is the electrical discharge machining

mgr inż. Rafał Nowicki, dr inż. Rafał Świercz, mgr inż. Adrian Kopytowski - Warsaw University of Technology, Poland; dr inż. Alena Vagaská - University of West Bohemia, Czech Republic

Corresponding author. rano@meil.pw.edu.pl 
assisted with ultrasonic vibration of the tool electrode or workpiece. Ultrasonic waves directly affect the dielectric liquid causing additional cavitation bubbles, which effectively clean the sparking gap from the machining products [9-13]. This phenomenon causes an increase in the number of plasma channels in the gap and an increase in the intensity of electrical discharges, which gives a measurable effect in the form of shortening the machining time. The condition of the surface layer of the workpiece will also have a different character, because the physics of phenomena occurring in the sparking gap during electrical discharge machning assisted with ultrasonic vibration is more complex than in the case of

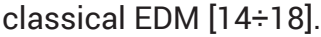

\section{Aim of the research and the workpiece}

Electrical discharge machining is mainly used to manufacture elements made of difficult to machine materials. In recent years, there has been an increase in the use of high-temperature alloys in the aerospace, energy, and automotive industries. One of these materials is the nickel-chromium alloy Inconel 718 . The characteristic feature of this alloy is the maintenance of high strength properties at increased temperatures. It is also characterized by resistance to degradation in corrosive and oxidizing environments. The low thermal conductivity of nickel superalloys causes heat concentrations in the shear zone, which makes the conventional machining of Inconel alloys very difficult and ineffective. The heat generated during machining usually changes the microstructure of the alloy and creates thermal stress that initiate the propagation of microcracks. Inconel 718 is used on a large scale in the aviation industry, in particular in hot sections of gas turbine engines, such as: turbine blades, discs, nozzles, valves, shields, shafts, combustion chambers, etc. These elements work in very difficult conditions and carry heavy loads. These parts are required to be characterized by high accuracy and high quality surface finish to ensure greater durability and fatigue strength.

The aim of the study was to analyze the impact of hybrid electrical discharge machining parameters assisted with ultrasonic vibration of the tool electrode on the surface texture of Inconel 718 . The parameters examined were the height roughness parameters: $S a, S t$ i $S z$.

\section{Methodology of experimental research}

Experimental studies on the impact of hybrid electrical discharge machining assisted with ultrasonic vibration on the condition of the top layer of Inconel 718 were carried out on the FORM 2-LC ZNC machine from Charmilles. The experiment was carried out using a copper tool electrode. The research involved polished, rectangular samples made of Inconel 718 with dimensions of $12 \times 12 \times 5 \mathrm{~mm}$. The machining process was carried out with full immersion of the workpiece and the working electrode in the dielectric - kerosene oil.

Ultrasonic head with piezoelectric transducer, which generated ultrasonic vibrations of the tool electrode, was used in the research. The head was mounted in a specially designed and made holder in the spindle of the machine in such a way that its feed movements are coupled with the working movements of the machine. The head was powered by an ultrasonic generator UGM 1000 with a constant frequency $f=20 \mathrm{kHz}$. The vibration amplitude was $A=20 \mu \mathrm{m}$.

The ultrasound head consisted of an ultrasound transducer generating mechanical vibrations, which were then amplified by a vibration concentrator and by appropriately selected geometric dimensions of the sonotrode and the tip fixing the sonotrode (Fig. 1). The working electrode was mounted at the end of the ultrasonic chain in the sonotrode.

Experiment was carried out according to orthogonal plan, which was five levels and two input factors On the basis of the analysis of technological tables of the generator characteristics of the machine for simple polarization and preliminary tests, the input parameters have been applied, which have the most important influence on the condition of the surface layer of the workpiece. The input parameters in the planned experiment were:

- current intensity in the range of $\mathrm{I}=1,7 \div 14 \mathrm{~A}$,

- pulse duration in the range of $\mathrm{t}_{\mathrm{on}}=5 \div 150 \mu \mathrm{s}$.

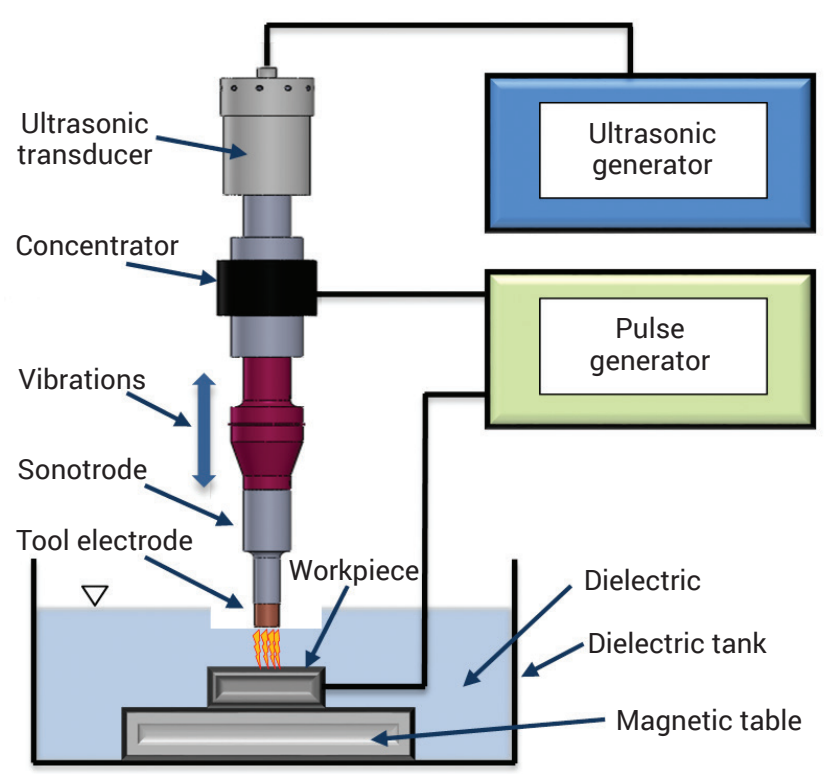

Fig. 1. Diagram of the electrical discharge machine assisted with ultrasonic vibration

The time interval $\left(\mathrm{t}_{\text {off }}\right)$ between pulses was assumed as the duty cycle of the impulse at the level of $\sigma=0.7$ according to the equation:

$$
\sigma=t_{\text {on }} /\left(t_{\text {on }}+t_{\text {off }}\right)=0.7
$$

The discharge voltage in the sparking gap was $U_{c}=50 \mathrm{~V}$. The samples were machined on a depth of $a_{p}=0.2 \mathrm{~mm}$. Kerosene oil was used as a dielectric.

The test result parameters were:

- parameter $S a$ - average arithmetic deviation of the height of surface irregularities from the reference plane,

- parameter $S t$ - the total height of the surface unevenness profile,

- parameter $S z$ - the largest height of the surface unevenness profile.

Surface topography measurements for each of the samples tested were performed using a high-quality Taylor Hobson FORM TALYSURF Series 2 scanning profilometer with TalyMap Expert surface analysis software. The surface of the sample with a cross section of $2 \times 2 \mathrm{~mm}$ was measured with a $10 \mu \mathrm{m}$ discretization step. The measurement was made using the continuous contact method using a contact sensor.

\section{Analysis of the results}

Table I presents the results of surface roughness measurements of samples made of Inconel 718 after electrical discharge machining assisted with ultrasonic vibration together with given input parameters. 
Table I. Results of surface roughness of Inconel 718 after electrical discharge machining assisted with ultrasonic vibration

\begin{tabular}{|c|c|c|c|c|c|c|}
\hline \multicolumn{7}{|c|}{ Parameters of the geometric structure of the surface } \\
\hline No. & $t_{o n}[\mu s]$ & $\mathrm{I}[\mathrm{A}]$ & $P[\mathrm{~mW}]$ & $S a[\mu \mathrm{m}]$ & $S t[\mu \mathrm{m}]$ & $S z[\mu \mathrm{m}]$ \\
\hline 1 & 10 & 2 & 0.1 & 3.22 & 34.8 & 30.8 \\
\hline 2 & 10 & 13.5 & 0.675 & 7.15 & 69.2 & 62.9 \\
\hline 3 & 145 & 2 & 0.1 & 1.53 & 22.3 & 14.3 \\
\hline 4 & 145 & 13.5 & 0.675 & 13.4 & 122 & 97.8 \\
\hline 5 & 5 & 8 & 0.4 & 6.57 & 56.9 & 46.3 \\
\hline 6 & 150 & 8 & 0.4 & 7.02 & 65.4 & 58.9 \\
\hline 7 & 78 & 1.7 & 0.085 & 1.35 & 18.5 & 15.4 \\
\hline 8 & 78 & 14 & 0.7 & 11.1 & 95.4 & 82.3 \\
\hline 9 & 78 & 8 & 0.4 & 7.45 & 68.7 & 60.3 \\
\hline 10 & 78 & 8 & 0.4 & 7.39 & 66.4 & 58.7 \\
\hline
\end{tabular}

The surface texture after electrical discharge machining assisted with ultrasonic vibration of the tool electrode is constituted by overlapping traces of individual electric discharges (Fig. 2). The formation of traces of machining is stochastic. The randomness of the surface texture is related to the physics of material removal in the electrical discharge machining process and the uneven amount of electrical discharges on the entire surface of the tool electrode. During machining, thousands of electrical discharges occur in the sparking gap, which generate the isotropic surface texture characteristic of EDM, resulting from overlapping craters from individual discharges.

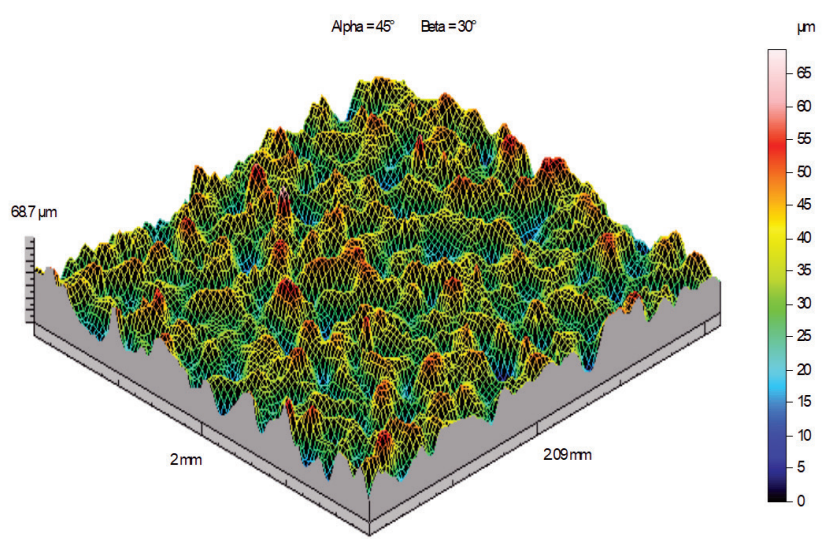

Fig. 2. Surface texture after electrical discharge machining assisted with ultrasonic vibrations of the tool electrode for the parameters: $\mathrm{U}_{\mathrm{c}}=50 \mathrm{~V}, \mathrm{I}=8 \mathrm{~A}, \mathrm{t}_{\mathrm{on}}=78 \mu \mathrm{s}$

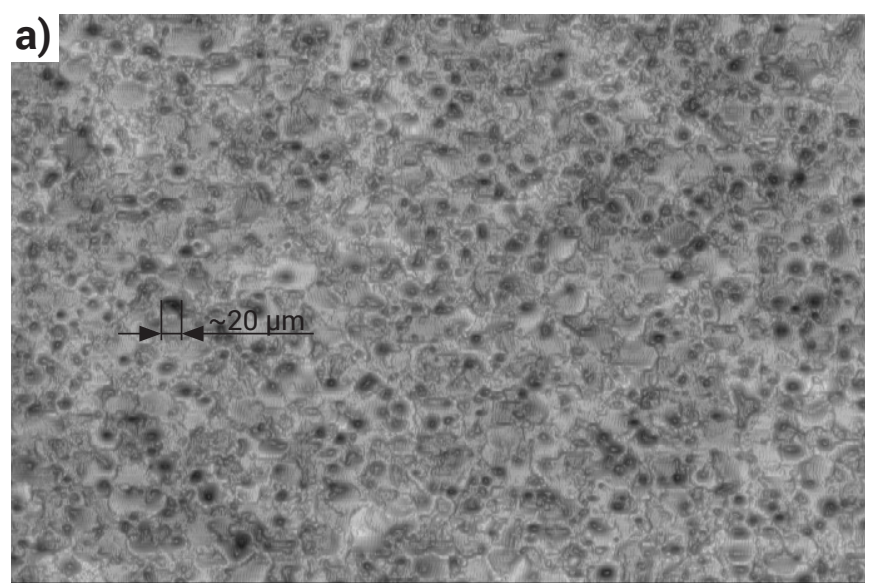

The surface after electrical discharge machining assisted with ultrasonic vibration is covered with a collection of characteristic craters whose shapes are close to the spherical bowls. For the low energy of electrical discharges, the surface after treatment is less damaged, the craters are evenly distributed, which can be seen in Figure 3, which show topographic maps of the outer surface layer after machining, photographed in the TalyMap Expert program, together with the corresponding machining parameters. The crater diameter for low electric discharge is $\sim 20 \mu \mathrm{m}$. For large discharges, the diameter of the craters is several times larger and amounts to $\sim 200 \mu \mathrm{m}$. In addition, at high current and pulse duration, the craters have irregular shapes and are unevenly distributed in the warp. This is due to the intensive heating and melting of the workpiece as a result of the high intensity of the electric current.

Craters on the surface have different depths, which is caused by the effect of ultrasonic waves. During machining, ultrasonic vibrations directly affect the dielectric liquid, forcing oscillations in the sparking gap of the ions emitted from the surface of the anode and electrons emitted from the surface of the cathode. This phenomenon creates an additional electromagnetic force that squeezes the plasma channel, and thus increases the density of the current flowing through this channel, which melts and generates craters on the surface with a smaller surface area and large depths.

Depending on the value of current and pulse time, significant differences in the morphological structure of the surface are noticeable (Fig. 4). The results of the surface roughness measurements indicate that the main factor that influences

Fig. 3. Visualization of the surface layer in photographic mode after electrical discharge machining assisted with ultrasonic vibration of the tool electrode for the parameters a) $U_{c}=50 \mathrm{~V}, \mathrm{I}=1.7 \mathrm{~A}$, ton $\left.=78 \mu \mathrm{s}, \mathrm{b}\right) \mathrm{U}_{\mathrm{c}}=50 \mathrm{~V}, \mathrm{I}=14 \mathrm{~A}, \mathrm{t}_{\mathrm{on}}=78 \mu \mathrm{s}$ 
a)

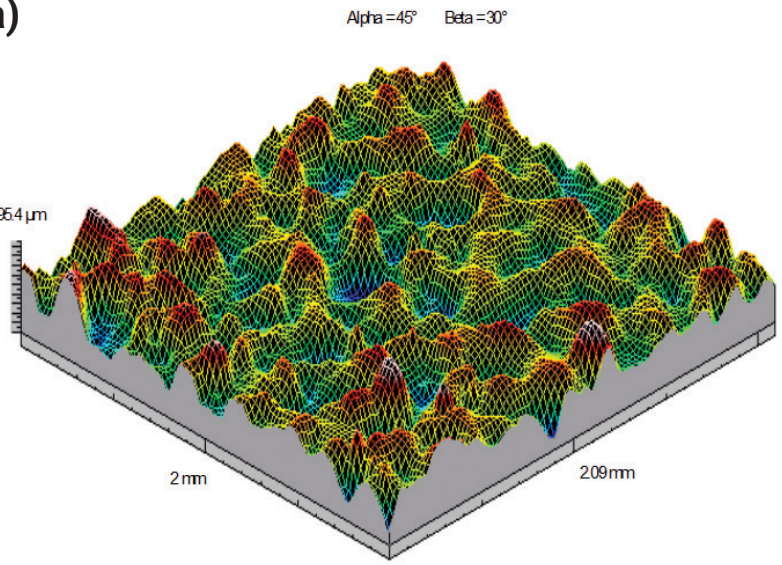

b)

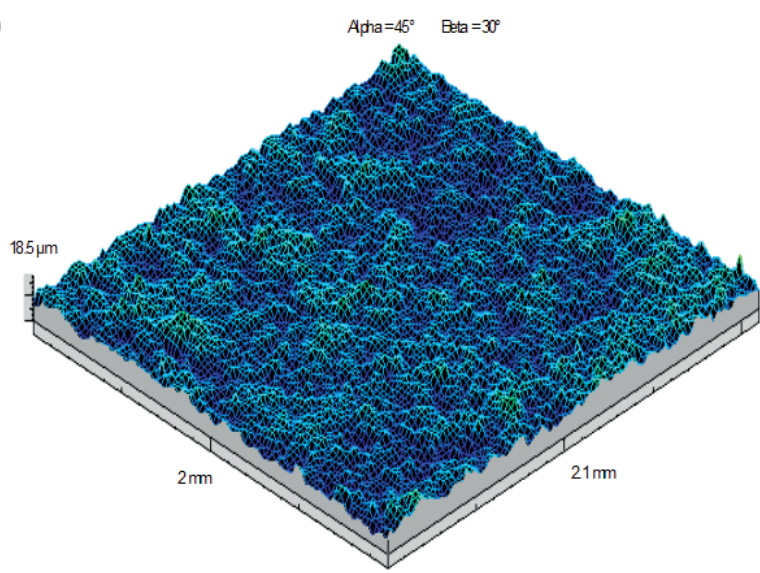

Fig. 4. Surface texture after electrical discharge machining assisted with ultrasonic vibration of the tool electrode for the parameters: a) $U_{c}=50 \mathrm{~V}$, $\left.\mathrm{I}=14 \mathrm{~A}, \mathrm{t}_{\mathrm{on}}=78 \mu \mathrm{s}, \mathrm{b}\right) \mathrm{U}_{\mathrm{c}}=50 \mathrm{~V}, \mathrm{I}=1.7 \mathrm{~A}, \mathrm{t}_{\mathrm{on}}=78 \mu \mathrm{s}$

the value of the altitude parameter $\mathrm{Sa}$ in the EDM+US treatment is the intensity of the electric current. The increase of current and pulse time favors a more intensive eroding of the workpiece in a single impulse leading to the creation of a larger spatial surface roughness. At small current values, the increase of the pulse time does not significantly affect the decrease of the Sa parameter (Fig. 5a). This can be explained by the amount of thermal energy generated and delivered to the material during electrical discharge, which is responsible for melting and evaporating the material depending on the discharge current. The higher the value of the electric current, the higher the discharge energy. By reducing the pulse duration at high currents, less thermal energy will be delivered to the workpiece and consequently craters with smaller depths will be created. Extending the pulse time leads to the generation of high roughness and deep craters. Topography of the surface in this case is characterized by large distances between the vertices of irregularities.

The St i Sz parameters provide information on the stability of electrical discharges. If these parameters have similar values, it indicates homogeneous electrical discharges in the sparking gap and the entire surface after treatment is characterized by an even value of depressions and peaks of the vertices. If these parameters are several micrometers bigger, this indicates the occurrence of inhomogeneous electric discharges in certain areas and the formation of craters or vertices with much larger dimensions than the average value. Analyzing Table I with the values of $S t$ and $S z$ parameters, it can be concluded that the share of random vertices and recesses is negligibly small, which indicates the stability of electrical discharges in the process of EDM assisted with ultrasonic vibrations. The high stability of the $E D M+U S$ process is due to a more intensive rinsing of the sparking gap due to ultrasonic vibrations of the tool electrode, which accelerates the de-ionisation of the discharge channel and creates favorable conditions for re-ionisation.

The largest difference in the values of $S t$ and $S z$ parameters occurs in the fourth measurement point $(I=13.5 \mathrm{~A}$ and $\left.t_{o n}=145 \mu \mathrm{s}\right)$. In this case, a large amount of electric discharge energy was used and a short break time between impulses. At high electric currents, the short time between the pulses does not lead to complete deionization of the discharge channel. In this case, a liquid pool of molten material may be present on the work surface, which has not crystallized or evaporated. When the electric discharge cycle is re-initiated, there is a very high probability that the discharge will occur in the same place and will be replicated on the surface of the pool of liquid material. This leads to the destabilization of electrical discharges in the sparking gap and the generation of larger profile elevations or deep craters, which translates directly into an increase in the value of $S t$ and $S z$ parameters.

As in the case of the parameter $\mathrm{Sa}$, the main factor determining the value of parameters $S t$ and $S z$ is the current intensity (Fig. 5b). Extending the pulse duration and current increases the diameter and power of the plasma channel, which results in an increase in the removal efficiency of the molten material. The energy of electric discharge is high, which favors the formation of deeper craters and higher peaks of unevenness, which affects the increase of $S t$ and $S z$ height parameters. a)

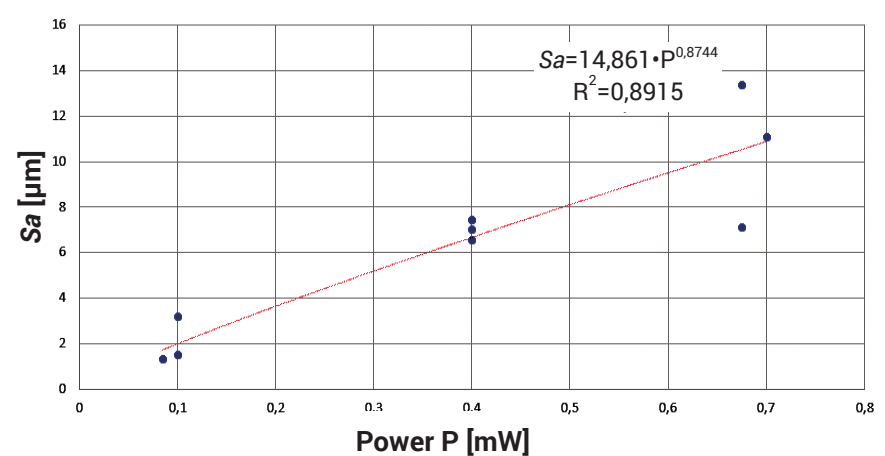

b)

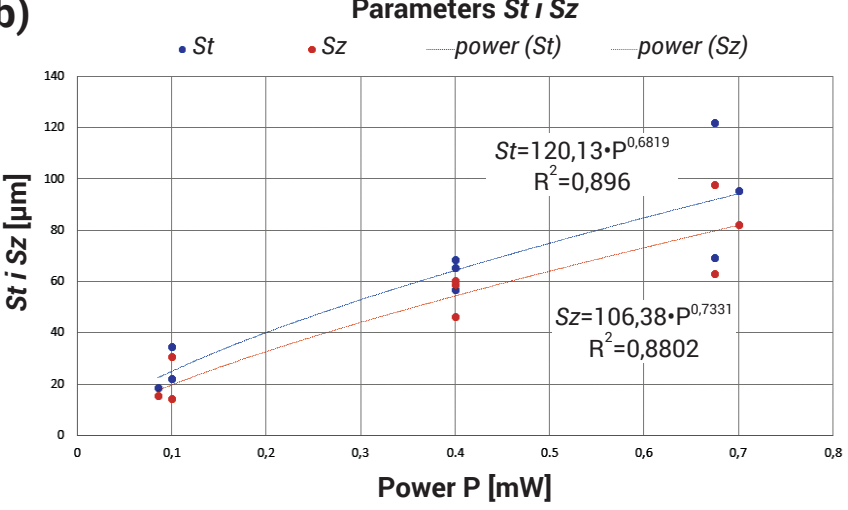

Fig. 5. Graph of surface roughness dependence on the process power. a) Sa parameter, b) St and Sz parameters 


\section{Summary}

Conducted experimental investigations of electrical discharge machining assisted with ultrasonic vibration of Inconel 718 indicate that the greatest influence on the surface texture parameters is the intensity of electric current. The increase in the current increases the diameter and power of the plasma channel, which results in the melting of a larger volume of material during a single pulse and the formation of deep craters that generate high surface roughness. The surface topography after electric discharge machining is formed as a result of overlapping traces of individual electrical discharges and has a point isotropic character. The smallest surface roughness after EDM + US treatment is obtained at low current intensity and long pulse duration. The number of random vertices and cavities of uneven surfaces after electrical discharge machining assisted with ultrasonic vibration is negligibly small, which indicates the stability of electrical discharges. The high stability of the EDM + US process is due to the increased intensity of rinsing of the interelectrode gap due to ultrasonic vibrations of the tool electrode, which accelerates the de-ionisation of the discharge channel.

The authors would like to thank the organizers of the conference of the Scientific School of Erosion Machining organized under the patronage of the Technology Section of the Committee on Machine Building of Polish Academy of Sciences for the possibility of presenting partial results of research published in this article.

\section{References}

[1] R. Nowicki, R. Świercz, D. Oniszczuk-Świercz, L. Dąbrowski, A. Kopytowski, Influence of machining parameters on surface texture and material removal rate of Inconel 718 after electrical discharge machining assisted with ultrasonic vibration, AIP Conference Proceedings, 2017, 020019 (2018).

[2] D. Oniszczuk-Świercz, R. Świercz, R. Nowicki, A. Kopytowski, L. Dąbrowski, Investigation of the influence of process parameters of wire electrical discharge machining using coated brass on the surface roughness of Inconel 718, AIP Conference Proceedings, 2017, 020020 (2018).

[3] A. Abdullah, R. Mohammad, A. Shabgard, T. Mohammad, Shervanyi-Tabar Effect of ultrasonic-assisted EDM on the surface integrity of cemented tungsten carbide (WC-Co), Int. J. Adv. Manuf. Technol. (2009), 268-280.

[4] A. Ruszaj, Charakterystyka współczesnych procesów wytwarzania elementów maszyn i narzędzi, The World of Machine Tools \& Tools (2014), vol. 9 (9-10), 23-29.

[5] A. Ruszaj, S. Skoczypiec, Obróbka elektroerozyjno-ścierna - wybrane zagadnienia, Mechanik (2015) nr 3, 210-215.

[6] M. R. Shabgard, B. Sadizadeh, H. Kakoulvand, The Effect of Ultrasonic Vibration of Workpiece in Electrical Discharge Machining of AISIH13 Tool Steel, World Academy of Science, Engineering and Technology (2009), 28.

[7] C. Praneetpongrung, Y. Fukuzawa, S. Nagasawa, K. Yamashita, Effects of the EDM Combined Ultrasonic Vibration on the Machining Properties of Si3N4, Materials Transactions (2010), vol. 51 (11), 2113-2120.

[8] G. Prihandana, M. Mahardika, M. Hamdi, K. Mitsui, Effect of low-frequency vibration on workpiece in EDM processes, Journal of Mechanical Science and Technology (2011), 25 (5), 1231-1234.

[9] J. Jakubowski, M. Bober, T. Rudaś, Struktura złączy lutospawanych metodą CMT stali ocynkowanej ogniowo, Welding Technology Review (2013), vol. 85 (9), 45-49.

[10] A. Singh, S. Kumar, V. Singh, Electrical Discharge Machining of Superalloys, A Review. IJRMET (2013) vol. 3 (2).
[11] R. Świercz, D. Oniszczuk-Świercz, L. Dabrowski, Electrical discharge machining of difficult to cut materials, Archive of Mechanical Engineering (2018), 65, 461-476, https://doi.org/10.24425/ame.2018.125437.

[12] I. Dul, J. Senkara, M. Bober, J. Jakubowski, Wpływ wysokotemperaturowego wygrzewania próżniowego na lutowność Inconelu 718 lutem Palnicro 36, Welding Technology Review (2013), vol. 85 (9), 15-19.

[13] T. Chmielewski, P. Siwek, M. Chmielewski, A. Piątkowska, A. Grabias, D. Golański, Structure and Selected Properties of Arc Sprayed Coatings Containing In-Situ Fabricated Fe-Al Intermetallic Phases, Metals (2018), 8, 1059, https://doi.org/10.3390/met8121059.

[14] K. Rokosz, T. Hryniewicz, D. Matýsek, et al. SEM, EDS and XPS Analysis of the Coatings Obtained on Titanium after Plasma Electrolytic Oxidation in Electrolytes Containing Copper Nitrate, Materials 9, 318, https://doi. org/10.3390/ma9050318.

[15] S. Spadło, P. Młynarczyk, K. Łakomiec, Influence of the of electrical dis charge alloying methods on the surface quality of carbon steel, Int. J. Adv. Manuf. Technol. (2017), 89, 1529-1534, https://doi.org/10.1007/ s00170-016-9168-1.

[16] D. Bańkowski, S. Spadło, The Aplication of Vibro - Abrasive Machining for Smoothing of Castings, Archives of Foundry Engineering (2017), 17, 169-173, https://doi.org/10.1515/afe-2017-0031.

[17] S. Spadło, W. Depczyński, P. Młynarczyk, Selected properties of high velocity oxy liquid fuel (HVOLF) - sprayed nanocrystalline WC-CO INFRALLOYTM S741 2 coatings modified by high energy electric pulse. Metalurgija (2017), 56, 412-414.

[18] B. Skowrońska, J. Szulc, T. Chmielewski, D. Golański, Wybrane właściwości złączy spawanych stali S700 MC wykonanych metodą hybrydową plazma+MAG, Welding Technology Review (2017), vol. 89 (10), 104-111.

(C) 2019 by the authors. Submitted for possible open access publication under the terms and conditions of the Creative Commons Attribution (CC BY) license (http://creativecommons.org/licenses/by/4.0/). 